\title{
The Contrastive Analysis of the Graduation Resources in China and US Press Briefings
}

\author{
Xin Bai \\ Changchun University of Science and Technology, China
}

\begin{abstract}
This is an age of media. In press conference, reporters ask the questions what he is curious about or interesting of. The spokesperson, as a host, is required to answer reporters' any question or doubt. There are large amounts of graduation resources in the press briefings. So this thesis will give a contrastive analysis of the graduation resources in China and US press briefings.
\end{abstract}

Index Terms - graduation resources, press briefings, contrastive analysis

\section{INTRODUCTION}

As the globalization and media industry develops, press conference has become an important channel for all works of society to know and understand an event or policy. Being an authentic language full of meaning, many scholars home and abroad have chosen the language from press conference as the focus of their studies. In other words, language from press conference has great potential to be studied and analyzed.

The methodology of this thesis is a combination of quantative and qualitive analysis. It includes four parts: the collection of text, statistics, analysis and result.The author uses the documents of press conference on the websites of China and US and analyzes the differences of graduation resources when they answer the same kind of topics quantatively and qualitively.

\section{THEORETICAL FRAMEWORK}

To explore the deep meanings of graduation resource, it is necessary to get some basic understanding of the basic theory of functional grammar. For example, interpersonal meaning, appraisal theory. Besides these, we still need to know some concepts about press conference. Only in this way, can we better understand the Chinese and American diplomat's implied meanings.

\section{A. Interpersonal Meaning in Functional Grammar}

The interpersonal meaning of language has been the subject investigated by many linguists for many years. Halliday proposes three meta-functions of language, which are the function of ideational, interpersonal and textual.

The interpersonal function of language "serves to establish and maintain social relations: for the expression of social roles, which include the communication roles created by language itself, for example the roles of questioner or respondent, which we take on by asking or answering a question; and also for getting things done, by means of the interaction between one person and another" (Halliday, 2000). Through the interpersonal meaning, "social groups are delimited, and the individual is identified and reinforced, since by enabling him to interact with others language also serves in the expression and development of his own personality."

\section{B. Summary of the Study on Graduation}

Graduation attends to grade phenomena whereby feelings are amplified and categories (Martin \& White, 2005). Graduation does not limit to one subsystem of Appraisal but involves the whole system. The distinguished feature of graduation is gradability. Martin and White (2008) have ever pointed that "the semantics of graduation should be the core of the appraisal system"(p.136). Force and focus are the two parts of graduation, which try to modify and limit attitudinal meanings and engagement system.

\section{Force}

Graduation is concerned with gradability. For attitude, since the resources are inherently gradable, graduation has to do with adjusting the degree of an evaluation - how strong or weak the feeling is.

Intensification deals with quality (slightly happy-very happy), process (slightly trouble us-greatly interrupt us) and modality (possible, probable, certain). The lexical intensifications of qualities are often employed to express the attitude, e.g. amazingly, dreadfully etc while the lexical intensification of processes are few used to convey the attitude, e.g. move swiftly, stare intently etc. There are mainly six modes that intensification operates: isolating, maximization, lexicalization, infusion, repetition and metaphor.

According to Martin \& White, quantification involves the values of the imprecise consideration of number, mass and extent. And it is typically via isolation, infusion and repetition acting as modifiers of the graduated entities. The 
following section will analyze the spokesperson press briefing in from the aspect of number, mass and extent as the analysis of quantification.

\section{Focus}

In general there seem to be more resources for turning the volume up than for turning it down: raise so touchy, infinitely more naked, quite clinical, most dangerous, lower a little upset, somewhat upset, the least bit more information. In the context of non-gradable resources, graduation has the effect of adjusting the strength of boundaries between categories, constructing core and peripheral types of things; this system is called "focus".

\section{The Linguistic Features of Press Briefing Discourse}

Press briefing is a public and special meeting which government sectors, social groups or individuals hold to invite reporters to join. Press briefing is an excellent model to combine publicity with news. Press briefing offers an opportunity for the sponsor to launch information and publicize itself to widespread media in the same platform and also provide reporters with a short cut to gain all-around and authoritative information in short time. Government press briefing is of the highest specification, biggest scale and maximum news value. Its imparting information is relatively direct, authoritative and abundant, which is the important news source of news media. Therefore, government press briefing is chosen as research object. Government press briefing here specializes government spreads information and increase influence to the public via media.

\section{Frankness}

Frankness means being direct and straightforward. With the purpose of gaining information and the lack of question time, journalists always ask questions frankly in order to getting more information. Frankness can be classified into going straight to questions and speaking bluntly.

\section{Vagueness}

Vagueness is also another important feature of press briefing discourse. Language vagueness expresses uncertainty and inaccuracy. Vagueness can contribute to successful communication. Communication needed language vagueness, which sounded strange. But if we completely obeyed conventional rules and eliminated the language vagueness, the communication would be totally dull and limit the function of communication and expression.

\section{The Unity of Objectivity and Subjectivity}

Objectivity is another indispensable important feature of press briefing discourse. First of all, press briefing is a mean of transmitting news. Therefore, it must objectively supply information so that there will not exist deviation. But at the same time, subjectivity is another feature of press briefing discourse. It doesn't conflict with objectivity. The first reason is that human beings are full of emotion. They will be affected by pleasure, anger, sorrow and joy. The spokesman has double identity: that is to say, he is not only a looker-on, but also a participant. On the one hand, as a looker-on, the spokesman must keep away from information and be objective in order to give information accurately, justly and factually.

\section{Euphemism}

A euphemism is a substitution of an expression that may offend or suggest something unpleasant to the receiver with an agreeable or less offensive expression or to make it less troublesome for the speaker as in the case of doublespeak.

\section{Argument}

In most situations, press briefing is a battle of words. The interests and purpose of journalists and spokesmen are different. The journalists will raise ridiculous questions, twist spokesman's remarks on purpose and even saddle their subjective inference and judgment on spokesmen.

\section{Humor}

Humor can ease tense atmosphere, refute the error by the way of transmitting information in meaning and humorous language. As a result, the communicative purpose can be achieved under relaxed circumstance. As a Chinese old saving goes, humor should go with time and circumstance.

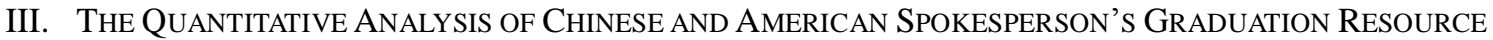

Nowadays, scholars have done many researches about press briefing discourse from multiple perspectives. Yang Xiujuan makes an analysis of remarks at press briefings held by Premier Zhu from the view of stylistics, semantics and pragmatics. Its purpose is to apply foreign theory to analyze our own native language material: Chinese, and the analysis demonstrates the tremendous vitality of language resources and the universality of foreign theory in application to Chinese language material. In the light of theories of pragmatic studies on international communication, Hu Gengshen and Wang Jing present the typical features of language use in press briefing discourses, i.e. frankness, fuzziness, euphimisticness, arguementiveness and humorousness. The researches of press briefing discourse are decentralized in different works, among which Zhao Hongvan's book stands out. She first introduces the developmental histories of Chinese and American government press briefing.

\section{A. Force Analysis}

As discussed in the former chapter, force should be the variable scaling of intensity, and the mode of it can be found widely in the media as well as its operation is always appeared in the expression of attitude. The daily press briefing in 
America should be the main way that the world understands the attitude of American government toward the international policy of America. In the next part, the thesis will analyze the daily press briefing in from the aspect of the two parts of force: intensification and quantification.

\section{Intensification}

In the former chapter, we have discussed that there are seven modes of intensification, which are mainly about the intensity of the values. In accordance with these seven modes, next section will give detailed analysis about the daily press briefings.

\subsection{Isolating}

Isolating, as one mode of intensification, refers to those isolated items independently achieve the task of setting the level of intensity. Isolating values are which realized through grammatical items whose sole function is to encode high, median and low grade of intensity. There are mainly three ways that isolated items appearing: up/down scaling of qualities; up/down-scaling of verbal process, up/down-scaling of modalities. In press briefing, we cannot find the isolated items that modify modalities, but the other ways have all appeared.

The number of isolated words grammatically in Chinese regular press conference is 145, which includes the repetition of some words. The following analysis will give the answers of these questions:

Quality isolated: most fateful, mere primitive, very beginning, clear, late, weak, great, whole, altogether.

Process isolated: really, actually, exactly, just, never, eventually, far more than this, reverently commit, only, just, firmly

\subsection{Infusion}

Quality infusion: calm and firm and united, faithful, contented, happy, joyous, warm, hot, scalding

Process infusion: only do, startled, frightened, terrified, fail, maximize, minimize, better, always, at least

\subsection{Repetition}

Quality repetition: to use one term like people for many times

Process repetition: the objective clause led by cost, see, how much, the prepositive phrase led by from

Repetition is easily discovered in numbers, as we all know, repetition is employed to strengthen the force and to make the effect of rhythm, but the language of English pays more attention to the economy of expression. When the president gives an inaugural speech or state of union address, he employs repetition to strengthen the force. For example:

The world is very different now. all forms of human poverty and all forms of human life.

Repetition is used to stress the new trend of the world situation and the challenge of future. So repetition should be the most common way that the Chinese political texts have employed.

\section{Quantification}

According to Martin \& White, quantification involves the values of the imprecise consideration of number, mass and extent. And it is typically via isolation, infusion and repetition acting as modifiers of the graduated entities. The following section will analyze the spokesperson press briefing in from the aspect of number, mass and extent as the analysis of quantification.

\subsection{Number}

... and to recognize we have so much more to gain by working together than finding the areas in which there are obvious disagreements and focusing more on them.

Imprecise numbers: so much more, more

In the spokesperson press briefing, there are many imprecise numbers showing the newly happened situations.

\subsection{Mass}

Imprecise numbers: tiny, large, gigantic etc.

In the press briefing, the reporters and the spokesperson mostly talk about the foreign affairs or international issues. These abstract topics are few about one concrete presence.

\subsection{Extent}

Extent has been divided into proximity and distribution, which involves with imprecise time and space. Generally speaking, the employment of extent is hard to find out in official text, which is determined by the style of political texts. It is acknowledged that political text is very formal and even every word is asked to be concise and exact. While press briefing is a instant response, the spokesperson cannot refer to the accurate materials. So he may employ ambiguous expression about proximity and distribution in terms of time and space.

Quantification, according to Martin and White, is to the imprecise one, which is very common to be used in this conference or briefing.

\section{B. Focus Analysis}

In terms of focus, the concept of grading has to do with sharpen or soften of categorical boundaries around experiential phenomena. A sharp focus represents a strengthening of the categorical meaning, and a soft Focus represents a weakening.

Sharpness is to make the effect of maximal investment by the authorial voice in the value position being advanced and hence to strongly align the reader into the value position being advanced.

Softness has mentioned that the softened term is a negative one, which is to show the lessening of the 
speaker/writer's investment in the value position. In briefing, the sentences that express the meaning of focus are 38:

Which ones were talking about? Just the whole territorial -

I will say in this set of circumstances it is not unusual that almost every country feels that they are on the defen sive,

Sharpeness: Just

Softeness: not unusual

The Chinese spokesperson is to express the attitude that these two ones are all important in the adjustment of income distribution in a reasonable manner.

In this example, the Chinese spokesperson has employed the maximizes real to modify, which has the attitudinal meaning: these five years are the real extraordinary time. Truly represents a sharpening of a categorical boundary. The word of truly not only has expressed the attitudinal meaning of the spokesperson, but also has the meaning of focus.

After analysis of the press conference of Chinese spokesperson, the sharpening items have been widely used while the softening items are not employed. From the above illustration, the attitudinal meaning, the context and culture all should be taken into account of our thinking the meaning of focus are often expressed by the word.

\section{The Qualitative ANALYsis OF THE ReASON}

After a quantitative analysis of the graduation resource, we have a visualized picture of this phenomenon in diplomatic world. But this is only a scientific data. For most diplomatic students or enthusiasts, they need a more conclusive answer about this question. In the following part, we will study the reason of the distribution feature of graduation resource in press conference.

\section{A. The Reason of the Distribution Feature of Graduation Resource in American Press Conference}

Generally speaking, American press conference feels like a seminar. The spokesperson and the reporters enjoy a relaxed environment. At the beginning, the spokesperson briefs the present situation of the world. The next step is reporter's free asking time.

\section{Social Status}

In America and many other western countries, the media is called the fourth power besides administration, legislation and judiciary. The media is a monitoring power in the society. So in the situation of press conference, the reporter appears as the equal one to the spokesperson. They can ask the spokesperson to answer their question. For example, even though a topic has been answered by the spokesperson, the reporter still can ask the spokesperson back to the topic. For example:

MS. PSAKI: Again, Brad, the Philippine Government is conducting an investigation. We encourage them to do so. I don't think I'm going to foray into this any further today.

\section{QUESTION: Can I go back to Japan?}

\section{QUESTION: Jennifer, can we go to Iraq?}

MS. PSAKI: Into - back to Japan?

From this example, we can see the press briefing is flexible. If the reporter feels an issue isn't answered well, he can ask the spokesperson to answer it again. This proves the high position of media reporter in America. Sometimes, a reporter can criticize administration to the spokesperson with upscaling words, like the case of Snowden.

\section{The Topic}

Most of time, the topic proposed by the reporters is about other countries, like China, Japan, Syria, Israel etc. We must admit no other countries can be a direct foe to the America. The motive of reporters to ask these questions is that America has enough influence on these topics no matter the international controversy and war nor the domestic affairs, such as human rights, air pollution even the misconduct of government officials of an independent country. So these questions give the American spokesperson an special speech rights to give their judgments on these issues, but also an pressure of interfering other nation's independent administration. We cannot ignore this psychological effects reflecting in American spokesperson's answers.

American spokesperson always uses "do not wish to"'avoid"mid value process to express their negotiator or neutral attitude on the issue of the dispute of sovereignty between China and Japan.

But American spokesperson always uses "pronounce"“I think"“proclaim". These dictions are employed to strengthen its involvement as a super power.

\section{The Culture}

As we all know, individual Culture is the foundation of America. So no matter in any situation, American would like others to make their own decision. For example, we can find "Viewer discretion is advised" at the very beginning of many American TV dramas. So as to the press conference, the spokesperson doesn't want to engage his too much judgment in his statement or answer.

It has close relationship between language and culture. Due to the appearance and development of language, culture has been emerged and passed down. In this world there is no culture without language, and also no language without culture; culture influences language while language reflects culture. As cross-cultural activity, press briefing is supposed to involve with cultures of different countries. The definition of culture includes many aspects: habits, beliefs, political stands, value systems etc. 


\section{B. The Reason of the Distribution Feature of Graduation Resource in Chinese Press Conference}

In China, since long time ago, the officer in government enjoys a lot of power. So, in Chinese press conference, the spokesperson gives less information about the situation.

\section{Social Status}

In China, the media doesn't have the function of being a watchdog of the administration. So the reporter only asks what they have interest and record what the spokesperson said, but cannot challenge the spokesperson's position in a press briefing. This decides why there are less upscaling words in the reporter's question in the press conference of China.

\section{The Topic}

As we know, China government pays more attention on its own affairs or concerned interests. China few interfere other countries' domestic issues, like human rights, political dissidents etc. So the topics on the China press conference are mainly about sovereignty.

\section{The Culture}

Usually, we think the culture of China is Confucian. Confucius emphasizes gentleness and peacefulness. But in the answer of Chinese spokesperson, there are $44 \%$ process strengthening words. These words are related to the present culture of China. Not only in public political texts, there are also many process strengthening words in our daily communication. So the spokesperson is influenced by the speech habit of common people.

\section{THE CONCLUSION}

Graduation is not only an isolated issue, which is easy to be affected by the factors like social status, topics, culture and psychology etc. Graduation can stimulate us to realize the communicative function of strengthening or weakening the semantic meaning, to employ reasonably the different level of linguistic resources and to accomplish the expression and communicative mission of different intention in press briefing more strategically.

Have you ever thought the system of appraisal theory is filled with the diction of diplomacy. This kind of study will be a new try and meaningful. On the basis of graduation under Appraisal, this thesis gives the detailed approach to the translation of the graduated words in the English version of press briefing. In this chapter, it will conclude the major findings, significance, and limitations of this study and also the recommendations for further research.

\section{A. Findings of This Study}

After a contrastive study of Chinese and US press briefings, the author has some findings listed below:

First, the distribution of force in press briefings is much more than the focus.

Second, the two parts of force (intensification and quantification) also have completely different distributions in press briefings. The number of intensification is more than the number of quantification.

Third, Intensification is explored through the six modes. However, still other graduated words have been made some adjustments, because of the special attitude in its contexts, the different cultures and different features of these two languages.

Fourth, Quantification is about the imprecise reckonings according to Martin and White. In contrast, we can easily find the precise items in press briefings but the imprecise ones are comparatively few.

Fifth, In comparison with the number of employments of force, the expressions of focus are comparatively few. Meanwhile the expressions of graduation are all sharpness without the appearing of softness.

\section{B. Significance of This Study}

Although the former studies have given more illustrations of the Appraisal in many kinds of discourses, few scholars choose the point of graduation to give research on the press briefings and its distributive features of the graduation resources. This study will deepen the researches on the graduation and expand the applications of graduation.

\section{Some Limitations of This Study and Recommendations for Further Research}

This study cannot be an exhaustive one of analyzing the translation of graduated words under Appraisal and there are still many limitations. Firstly, in the Appraisal System, graduation is to scale the other two subsystems: attitude and engagement. This thesis just talks about the graduation without touching upon the others. Secondly, there are many causes to the changes of graduated words in the text; especially the differences from the aspects of culture and language, but this thesis only give several points due to the limited time and space.

This thesis only takes the press conference of Chinese Government, and the press briefings of US Government in other years have not been included. The graduated words in these press briefings still need to make further research so as to exactly construe the attitudinal meaning of the spokesperson.

\section{REFERENCES}

[1] Cui Weina. (2012). The English Translation of 2011 Report on the Work of the Government: A Study on Graduation under Appraisal.

[2] Halliday, M.A.K. (2000). An Introduction to Functional Grammar. Beijing: Foreign Language Teaching and Research Press. 
[3] Martin J.R. (2010). Discourse Semantics. Shanghai: Shanghai Jiao Tong University Press.

[4] Martin J.R. \& P.R.R. White. (2005). The Language of Evaluation: Appraisal in English. London: Palgrave Macmilan.

[5] Martin,J.R. (2004). English Text: System and Structure. Beijing: Peking University Press.

[6] Martin,J.R. (1995). Interpersonal Meaning, Persuasion, and Public Discourse: Packing semiotic punch. Australian Journal of Linguistics, 15, 3-67.

[7] Thompson,G \& S.Hunston. (2000). Evaluation in Text: Authorial Stance and the Construction of Discourse. Oxford: Oxford University Press.

[8] Van Dijk,T.A. (1995). Discourse Analysis as Ideology Analysis. Language and Peace, 10, 47-142.

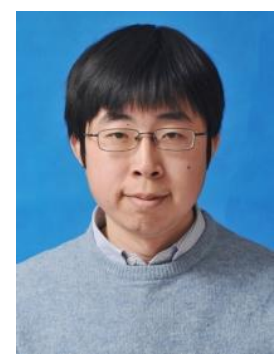

Xin Bai was born in Tongliao, China in 1984. He received his BA degree in English from Inner Mongolia University for the Nationalities, China in 2007.

$\mathrm{He}$ is currently a master of arts in the School of Foreign Languages, Changchun University of Science and Technology, Changchun, China. His research interest is linguistics and discourse analysis. 